\title{
REDES SOCIAIS E GERATIVIDADE: A EXPERIENNCIA DO PROGRAMA IDOSOS ON-LINE
}

\author{
Glaucia Mauch de Carvalho1 \\ Roberta dos Santos Tarallo² \\ Samila Sathler Tavares Batistoni ${ }^{3}$ \\ Meire Cachioni ${ }^{4}$
}

resumo

O projeto /doso On-line é um espaço de inclusão digital para idosos que possibilita o encontro intergeracional e ações gerativas. Buscou-se, neste estudo, identificar os indicadores de geratividade na velhice, bem como os possíveis impactos e repercussões dos idosos ao participarem dessa oficina. Aplicou-se um questionário sociodemográfico, um questionário semiestruturado sobre a utilização do computador e uma Escala de Geratividade. O tratamento e a análise dos dados foram realizados por meio da utilização do programa

\footnotetext{
1 Graduada em Gerontologia. E-mail: glaucia.carvalho@usp.br.

2 Graduada em Gerontologia. Mestranda em Gerontologia. E-mail: r_tarallo@yahoo.com.

3 Psicóloga. Docente do curso de Graduação em Gerontologia da Escola de Artes, Ciências e Humanidades da Universidade de São Paulo. E-mail: samilabatistoni@usp.br.

4 Psicóloga. Docente do curso de Graduação em Gerontologia da Escola de Artes, Ciências e Humanidades da Universidade de São Paulo. E-mail: meirec@usp.br.
} 
SPSS. Os resultados apontaram que a maioria dos participantes são mulheres com mais de 70 anos, e com ensino fundamental incompleto. Sobre as ações gerativas, dos vinte itens da Escala, seis apresentaram diferenças estatisticamente significativas entre as médias das duas coletas realizadas (antes e posterior à participação no Módulo III) 1. Tenho desenvolvido ações que têm tido impacto noutras pessoas; 2. Penso que serei lembrado durante bastante tempo depois de morrer; 3. Procuro partilhar e ensinar aos outros aquilo que sei fazer; 4. Os outros dizem que sou muito prestativo; 5. As pessoas me procuram para se aconselharem; 6. Sinto que não tenho feito nada que vá sobreviver à minha morte. A maior parte dos participantes (95\%) possuíam computadores em casa com acesso à internet e estavam interessados em notícias, pesquisa e diversão. Esses participantes perceberam as redes sociais como ferramentas para comunicação, conhecimento e interação com o mundo. Identificou-se que as redes sociais podem contribuir para a presença, o fortalecimento, e a busca de ações ou atitudes que favorecem a geratividade.

palavras-chave

Redes sociais. Idoso. Informática. Geratividade.

O envelhecimento populacional é um fenômeno que vem ocorrendo em todo o mundo (NERI, 2007). Segundo as projeções da Organização Mundial de Saúde (2003), o Brasil, em 2025, será o sexto país do mundo com o maior número de idosos (FERREIRA; CORRÊA; BANHATO, 2010). Essa população representa uma oportunidade de mercado para a tecnologia da informação, bem como um desafio em oferecer produtos essenciais e adequados (WANG; RAU; SALVENDY, 2011).

A senescência pode desencadear alterações biológicas, como a baixa acuidade visual e a precisão motora reduzida; e psicológicas, como a lentidão da resposta a estímulo. Nesse ínterim, a tecnologia, quando empregada conforme essas necessidades, possibilita a minimização das incapacidades físicas e cognitivas, presentes em alguns idosos (SILVEIRA, 2010; WANG; RAU; SALVENDY, 2011). 
Quando ocorre a falta de acesso e de familiarização com a linguagem do computador e da internet, os avanços tecnológicos também podem gerar limitações, resultando, assim, em exclusão de quem não compreende essas mudanças (HILT; LIPSCHULTZ, 2004; SALES et al., 2009; SILVEIRA, 2010).

Desse modo, a ampliação de programas de inclusão digital se faz imprescindível, no sentido de suprir a demanda dos idosos e promover a disseminação de conhecimento, a interação e a participação social (SALES et al., 2009). Vale destacar, que os idosos alfabetizados digitalmente apresentam maior autonomia com relação à utilização dos recursos tecnológicos, principalmente, quando os usufruem de forma crítica e criativa (GOULART, 2007).

Deve-se considerar que o mundo virtual fomenta e determina novos paradigmas temporais e espaciais, uma vez que as distâncias intransponíveis, que gerariam limites físicos, são adaptadas. A tecnologia trabalha em tempo imediato, tornando-se alternativa às limitações do próprio corpo (AZEVEDO; CÔRTE, 2009).

Diante disso, muitos idosos têm interesse em dominar a ferramenta tecnológica com o objetivo de se comunicarem (BOULTON-LEWIS et al., 2007). As mídias sociais são fonte para essa motivação, pois permitem a conexão entre pessoas por meio de afinidades, o estabelecimento de suporte social e a construção de redes sociais com o intuito de disseminar informações de conteúdos variados (HOGEBOOM et al., 2010).

As redes sociais têm se tornado uma alternativa de contato com o mundo externo real e virtual, contribuindo para o sentimento de pertencimento. O blog é considerado um dos acontecimentos mais significativos da cultura digital, na contemporaneidade, (CHASSOT, 2005) e atua como um diário online pessoal ou coletivo, que pode ser acessado livremente pela web. O facebook também emerge como uma das redes sociais digitais mais acessadas em todo o mundo e trata-se de um espaço de encontro, que permite compartilhar assuntos e interesses comuns, promovendo a interação social (PÁSCOA, 2012).

Com isso, os estudos têm destacado os benefícios que a inclusão digital e as redes sociais podem proporcionar à velhice, dentre eles: participação e aprimoramento em atividades sociais e intelectuais, estímulo cognitivo e alteração da perspectiva de isolamento (CZAJA et al., 1993; JONES; BAYEN, 1998; MORRELL; MAYHORN; BENNETT, 2000; KACHAR, 2001; SALES, 2002; BALBONI; SCWARTZ, 2005). Atuam ainda, como mecanismo de ação para a promoção do bem-estar e da qualidade de vida, pois ajudam a controlar o estresse e a reduzir a depressão (BOULTON-LEWIS et al., 2007; HOGEBOOM et al., 2010) além de serem facilitadoras no processo de geratividade, segundo Banhato e colaboradores (2007). 
A geratividade se refere às motivações e ao envolvimento em atividades tendo em vista a sua continuidade e existência (NERI, 2005). O estágio gerativo, proposto por Erik Erikson (WEILAND, 1989), é o mais longo do ciclo de vida e culmina na velhice. A pessoa tende a se empenhar na transmissão de seus conhecimentos, na convivência com gerações mais novas e, com isso, transmite sua bagagem cultural acumulada ao longo dos anos vividos (ERIKSON, 1998). Assim, a geratividade reflete os esforços de se envolver em ações cujo objetivo é realizar algo que seja interessante e, mesmo, importante às próximas gerações (BERMAN, 1995).

A geratividade pode ser relacionada com a cultura, por transpassar uma sensação de ordem e de direção a ser seguida, por se tornar um espelho diante do que foi e está sendo vivido, fornecendo ações gerativas (BERMAN, 1995). Desse modo, as pessoas desejam ser gerativas de diversas maneiras e este desejo é estimulado e encorajado por interações advindas do ambiente social e educativo.

As ações gerativas, no contexto da educação permanente, estão também inseridas em programas de inclusão digital. O processo educativo deve ser realizado de forma a atender a individualidade e as especificidades dos sujeitos, quanto às suas facilidades e, ou, às suas dificuldades para a apropriação das tecnologias de informação (SILVEIRA, 2010). Logo, as Universidades Abertas à Terceira Idade vêm executando programas que visam à educação e à integração dos idosos, contribuindo para o desenvolvimento cognitivo dos idosos (ORDONEZ; YASSUDA; CACHIONI, 2010).

Neste contexto, a Universidade Aberta à Terceira Idade, da Escola de Artes, Ciências e Humanidades da Universidade de São Paulo (UnATI/EACHUSP), criou o projeto Idosos On-line, que visa a inclusão digital de pessoas idosas e a educação gerontológica, por meio do uso do computador, bem como a promoção do contato intergeracional, suscitando, assim, ações gerativas.

Buscou-se identificar no projeto Idoso On-line os possíveis impactos e repercussões dos idosos ao participarem dessa oficina, como também os indicadores de geratividade na velhice. 
truindo Nossa Rede Gerontológica, do projeto Idosos On-line, realizado no Laboratório de Informática da UnATI/EACH-USP.

Quanto aos critérios de inclusão da investigação, idosos que haviam concluído os Módulos I e II, matriculados e participantes do Módulo III. Sobre os critérios de exclusão, idosos que não frequentaram os Módulos I e II e não participantes do Módulo III.

O projeto Idosos On-line tem como objetivo promover a inclusão digital, por meio de oficinas desenvolvidas em três módulos sequenciais e semestrais: Módulo I - Alfabetização Digital (idosos sem conhecimento em informática); Módulo II - Aprendendo na Rede (idosos que participaram do Módulo I e possuem conhecimentos básicos em informática) e o Módulo III - Construindo Nossa Rede Gerontológica, que tem a finalidade de introduzir as principais redes sociais: facebook e blogs coletivos.

O Módulo III: Construindo Nossa Rede Gerontológica foi constituído por duas turmas, cada uma com 10 alunos-idosos, que foram orientados por 10 graduandos do Curso de Bacharelado em Gerontologia da instituição. No total, foram realizados 14 encontros, durante o semestre letivo, com duração de 120 minutos cada, sendo 20 minutos reservados para a introdução do tema do dia, 80 minutos de interação e uso da(s) ferramenta(s) e 20 minutos para esclarecimentos de dúvidas, conforme a seguinte estrutura:

1. Introdução do tema do dia: Ferramenta que seria utilizada (20 minutos).

2. Interação e uso da(s) ferramenta(s) proposta(s) com duração de 60 minutos, com 15 minutos para esclarecimentos de dúvidas.

No Quadro 1 estão presentes os conteúdos desenvolvidos nos 14 encontros. 
Quadro 1 - Temas e atividades desenvolvidas no Módulo III, Oficina Idosos On-line, EACH-USP, 2012.

\section{Temas das Aulas}

\begin{tabular}{|c|c|}
\hline Primeira sessão & $\begin{array}{l}\text { Exposição dos objetivos da oficina, expectativa dos participantes; } \\
\text { avaliação e revisão dos módulos anteriores: Geratividade, Interação } \\
\text { Social, Inclusão Digital, Mídias Sociais, UnATI. }\end{array}$ \\
\hline Segunda sessão & Apresentação dos temas centrais da oficina \\
\hline Terceira sessão & Aula expositiva do Facebook \\
\hline Quarta sessão & Construção do Facebook \\
\hline Quinta sessão & Explorando os recursos do Facebook - Postagem de mensagens \\
\hline Sexta sessão & Postagem de fotos e vídeos. \\
\hline Sétima sessão & Aula expositiva do Blog "O que é criação"; Escolha dos temas. \\
\hline Oitava sessão & Construindo Blog coletivo. \\
\hline Nona sessão & $\begin{array}{l}\text { Busca avançada na internet de assuntos variados de interesse dos } \\
\text { idosos para postagem no Blog. }\end{array}$ \\
\hline Décima sessão & Pesquisa campo referente Atividades fornecidas na UnATI. \\
\hline $\begin{array}{l}\text { Décima primeira } \\
\text { sessão }\end{array}$ & Postagem do material no Blog. \\
\hline $\begin{array}{l}\text { Décima segunda } \\
\text { sessão }\end{array}$ & $\begin{array}{l}\text { Pesquisa de temas Gerontológicos sugeridos pelos alunos-idosos } \\
\text { (Depressão; Direitos do Idoso; Cognição, Memória e Demência; } \\
\text { Doença de Alzheimer; Nutrição e Envelhecimento, Quedas em } \\
\text { Idosos e Estresse). }\end{array}$ \\
\hline Décima terceira sessão & Postagem do material no Blog. \\
\hline Décima quarta sessão & $\begin{array}{l}\text { Avaliação final; uso livre do Facebook para duvidas e informações } \\
\text { adicionais de Blog. }\end{array}$ \\
\hline
\end{tabular}

Com os conhecimentos adquiridos na oficina, por intermédio de ferramentas de comunicação, os idosos desenvolveram um blog coletivo e aprenderam a inserir imagens e informações de cunho gerontológicos.

Para a coleta dos dados, utilizou-se um protocolo contendo: 1) questionário sociodemográfico, com o intuito de conhecer o perfil dos participantes; 2) questionário semiestruturado intitulado: “Utilização da internet e a participação nas redes de relacionamento", a fim de levantar possíveis variáveis que beneficiam, dificultam ou impedem a utilização da internet; e 3) Escala 
de Geratividade. Utilizou-se a versão portuguesa da Loyola Generativity Scale ADAMS; AUBIN, 1992) de Ferreira Alves e colaboradores (2006). Trata-se de uma escala com 20 itens, cujos itens refletem preocupação gerativa cujo construto compõem-se das dimensões da geratividade encontradas na literatura como (1) a transmissão de conhecimentos e competências a outros, nomeadamente à geração seguinte, (2) a contribuição para a melhoria das condições de vida na comunidade, (3) realizações susceptíveis de virem a ser recordadas por um longo período de tempo, (4) ações criativas ou atuação produtiva e (5) o cuidado e a assunção de responsabilidade por outras pessoas. Apesar da escala abarcar estas várias dimensões da geratividade, os seus autores propõem a extração de apenas um escore global que resultará do somatório das pontuações atribuídas pelos respondentes a cada item (somando-se, na forma inversa, os itens apresentados sob forma de negação). Os itens são avaliados de acordo com uma escala que explicita a frequência com que a asserções neles contidas se aplicam ao inquirido, indo desde "nunca se aplica" (0), até "aplica-se com muita frequência" (3). Estudo original e da versão portuguesa encontraram índices de consistência interna de 0.79 a 0.82 (Alpha de Cronbach). Para uso com idosos brasileiros, uma análise da equivalência entre os vocábulos foi realizada por um linguista, havendo sugestões de alteração nos itens 8,10,17,19,20. Como não há um ponto de corte específico para idosos, o presente trabalho utilizou-se apenas da distribuição de frequência às respostas dadas a cada item antes e após a intervenção.

O protocolo de pesquisa foi aplicado em dois momentos: no primeiro e no último dia da oficina. Porém, aplicou-se a avaliação socioeconômica apenas no início do Módulo.

Ressalta-se que todas as questões éticas foram norteadas pelos princípios da Resolução no 196/96 sobre as Diretrizes e Normas Reguladoras de Pesquisa em Seres Humanos (BRASIL, 1996).

Com relação ao tratamento e à análise dos dados, utilizou-se o Software Statistic Package for Social Science (SPSS), versão 20 for Windows. As informações obtidas por meio dos questionários foram submetidas à análise estatística descritiva, para frequência, tendência central e dispersão. Já para a Escala de Geratividade, os itens, da primeira e da segunda coleta, foram correlacionados utilizando-se qui-quadrado, com $\mathrm{p}<0,05$ para valores estatisticamente significativos. 
Apresentar-se-á o perfil sociodemográfico dos participantes do Módulo III da oficina Idosos On-line; a relação entre a utilização da tecnologia na velhice, as contribuições e as percepções perante as redes sociais (facebook e blog) para a promoção do envelhecimento, bem como os contributos da geratividade.

\section{1 perfil sociodemográfico dos entrevistados}

O estudo foi composto por 20 participantes regularmente matriculados no Módulo III. Na Tabela 1 verifica-se os dados sociodemográficos dos participantes, cujas variáveis investigadas foram sexo, idade e escolaridade.

Tabela 1 - Perfil sociodemográfico dos participantes do Módulo III, oficina Idosos On-line, EACH-USP.

\begin{tabular}{l|c|c}
\hline \multicolumn{1}{c|}{ Variável } & $\mathrm{n}=\mathbf{2 0}$ & $\%$ \\
\hline Gênero & & \\
\hline Feminino & $\mathbf{1 8}$ & $\mathbf{9 0 , 0}$ \\
\hline Masculino & & 10,0 \\
\hline $\mathbf{1 d a d e}$ & & 5,0 \\
\hline $\mathbf{5 6 - 6 0}$ & 01 & 20,0 \\
\hline $\mathbf{6 0 - 6 4}$ & 04 & 25,0 \\
\hline $\mathbf{6 5 - 6 9}$ & 05 & 35,0 \\
\hline $\mathbf{7 0 - 7 4}$ & 07 & 10,0 \\
\hline $\mathbf{7 5 - 7 9}$ & 02 & 5,0 \\
\hline $\mathbf{8 0 - 8 5}$ & 01 & \\
\hline
\end{tabular}




\begin{tabular}{l|c|c}
\hline Escolaridade & & \\
\hline Ensino Fundamental Incompleto & 08 & 41,0 \\
\hline Ensino Fundamental Completo & 04 & 17,9 \\
\hline Ensino Médio Incompleto & 04 & 5,1 \\
\hline Ensino Médio Completo & 02 & 25,6 \\
\hline Ensino Superior Incompleto & 00 & 0,00 \\
\hline Ensino Superior Completo & 02 & 10,3 \\
\hline
\end{tabular}

Na variável sexo, predominou o feminino $(90,0 \%)$ em relação ao masculino (10,0\%). Assim como ocorre nas sociedades modernas, o processo de feminização da velhice esteve presente no Módulo III, dos Idosos On-line. A predominância feminina entre os idosos brasileiros é um fenômeno muito mais urbano e está relacionada com a menor taxa de mortalidade das mulheres em relação aos homens (CAMARANO; KANSO, 2011), possivelmente, devido à menor exposição a determinados riscos que essas sofreram, bem como ao maior cuidado com a saúde que elas tiveram. As mulheres também participam muito mais de atividades fora do ambiente doméstico, como cursos, viagens e trabalho voluntário, em relação aos homens, que, muitas vezes enfrentam mais dificuldades de se adaptarem à aposentadoria (CAMARANO; KANSO, 2011).

Com relação à idade, $45 \%$ tinham entre 60 e 69 anos. Essa faixa etária é caracterizada como idosos-jovens, ou seja, a própria velhice sofreu denominações distintas para melhor compreender as necessidades e demandas de cada faixa etária (FERREIRA; CORRÊA; BANHATO, 2010; SILVA, 2011). Destaca-se, neste estudo, a presença mais expressiva, no total de $75 \%$, de idosos-médios, com mais de 70 anos de idade e, até mesmo, a participação de um octogenário.

Sobre a variável escolaridade, $41,0 \%$ dos idosos cursaram o ensino fundamental incompleto; $17,9 \%$ declararam ter completado o ensino fundamental; $5,1 \%$ não completaram o ensino médio; $25,6 \%$ fizeram o ensino médio completo e 10,3\% frequentaram o ensino superior completo. Contrariando, assim, a afirmação de Boulton-Lewis e colaboradores (2007) sobre a influência da pouca escolaridade e da condição socioeconômica baixa serem fatores que predispõem o afastamento do idoso frente ao novo, gerando uma relação aversiva entre aprendizagem e tecnologia. 
A Tabela 2 apresenta dados sobre a utilização e a posse do computador, bem como o uso da internet na residência por parte dos participantes do Módulo III.

Tabela 2 - Utilização e posse de computador e acesso à internet na residência dos participantes do Módulo III, oficina Idosos On-line, EACH-USP.

\begin{tabular}{l|c|c}
\hline \multicolumn{1}{c|}{ Variáveis } & $\mathrm{n}=\mathbf{2 0}$ & $\%$ \\
\hline Utiliza o computador & & \\
\hline Sim & 19 & 5 \\
\hline Não & 01 & \\
\hline & & \\
\hline Possui computador na residência & 19 & 5 \\
\hline Sim & 01 & \\
\hline Não & & \\
\hline Conexão de internet na residência & 16 & \\
\hline Sim & 04 & 20 \\
\hline Não & & \\
\hline
\end{tabular}

De acordo com a Tabela 2, 95\% dos participantes utilizavam e possuíam computador na residência e 5\% negaram essas possibilidades. Quanto ao acesso à internet domiciliar, $80 \%$ dos idosos responderam que possuíam, contra $20 \%$ que não tinham, mas que afirmaram utilizar os ciberespaços, conhecidos como lanhouse.

Conforme constatação de outros estudos, os idosos estão entre os consumidores de informação on-line mais interessados. Para muitos deles, o mundo virtual está se tornando uma alternativa funcional em relação à televisão, uma vez que os sites de informação parecem ser mais importantes e esclarecedores (HILT; LIPSCHULTZ, 2004).

No Brasil, segundo a Pesquisa Nacional por Amostra de Domicílio (PNAD), de 2012, nos últimos seis anos cresceu o número de pessoas com mais de 60 anos com conexão à internet $(20,5 \%)$, principalmente, para se comunicarem, sendo o índice, para essa faixa etária, muito próximo do porcentual entre pessoas com 16 a 24 anos, que mais acessam a internet (CETIC, 2013). 
Hogeboom e colaboradores (2010) corroboram a ascensão da utilização das tecnologias pelos idosos com o fato desses terem, por vezes, mais tempo livre do que as gerações mais jovens, possibilitando, assim, fazer mais uso da internet. Outros fatores que influenciam a aceitação e o uso da tecnologia pelos idosos são compreendidos pela aquisição de novas experiências, pela melhora da auto eficácia, pela possibilidade de se comunicarem e por se manterem atualizados (WANG; RAU; SALVENDY, 2011).

Com relação à utilização da internet e das redes sociais, a Tabela 3 evidencia os principais interesses dos quais os participantes, do Módulo III, apresentaram.

Tabela 3 - Interesses pela internet dos participantes do Módulo III, oficina Idosos On-line, EACH-USP.

\begin{tabular}{l|c|c}
\multicolumn{1}{c|}{ Variável } & $\mathbf{n = 2 0}$ & $\%$ \\
\hline Páginas de Acesso (Nível de interesse) & & 5 \\
\hline Chats (MSN) & 03 & 9 \\
\hline Sites de relacionamento & 05 & 17 \\
\hline Pesquisa & 10 & 19 \\
\hline Notícias & 11 & 10 \\
\hline Diversão & 06 & 10 \\
\hline Educação & 06 & 10 \\
\hline Esportes & 06 & 9 \\
\hline Informação sobre política & 05 & 4 \\
\hline Comprar & 02 & 7 \\
\hline Outros & 04 & 100 \\
\hline Total & 20 & \\
\hline
\end{tabular}

As páginas da internet que os participantes mais se interessaram foram $(19 \%)$ notícias, $(17 \%)$ pesquisa, (10\%) diversão, $(10 \%)$ educação, (10\%) esportes, $(9 \%)$ informação sobre política, $(9 \%)$ sites de relacionamento, $(7 \%)$ outros (que inclui e-mail), (5\%) salas de bate-papo, como chats/MSN, e (4\%) compras.

Estudos corroboram com a presente esta investigação, uma vez que, apresentam as seguintes atividades pelas quais os idosos têm interesse ao utilizarem a internet: enviar ler e-mails; fazer a manutenção da própria página ou blog; procurar notícias e eventos; chat e mensagens instantâneas; jogos; ver 
a previsão do tempo; procurar ou comprar bens e serviços; executar operações bancárias; pesquisas diversas; baixar programas, músicas, filmes ou imagens; participar de aulas e cursos on-line (HILT; LIPSCHULTZ, 2004; WANG; RAU; SALVENDY, 2011).

\subsection{Contribuições das redes sociais para o envelhecimento.}

Na Tabela 4 buscou-se investigar as percepções dos idosos com relação às redes sociais (facebook ou blog), bem como as contribuições dessas ao serem utilizadas no dia a dia.

Tabela 4 - As redes sociais e as percepções dos participantes do Módulo III, oficina Idosos On-line, EACH-USP.

\begin{tabular}{l|c|c|c|c}
\hline \multirow{2}{*}{ Variáveis } & \multicolumn{2}{c|}{$\mathbf{1}^{\text {a }}$ coleta } & \multicolumn{2}{c}{$2^{\text {a coleta }}$} \\
\cline { 2 - 5 } & $\mathrm{n}=\mathbf{2 0}$ & $\%$ & $\mathrm{n}=\mathbf{2 0}$ & $\%$ \\
\hline $\begin{array}{l}\text { Rede social } \\
\text { - Facebook (vínculos de amizade) }\end{array}$ & & & & \\
\hline Sim & 4 & 20 & 20 & 100 \\
\hline Não & 16 & 80 & 0 & 0 \\
\hline & & & & \\
\hline Rede social & & & & \\
\hline Blog (contribuições cotidianas) & & & & \\
\hline Comunicação & 4 & 20 & 7 & 35 \\
\hline Entretenimento & 1 & 5 & 2 & 10 \\
\hline Conhecimento & 2 & 10 & 6 & 30 \\
\hline Interação com o mundo & 13 & 65 & 3 & 15 \\
\hline Facilidade & 0 & 0 & 1 & 5 \\
\hline Outros & 0 & 0 & 1 & 5 \\
\hline
\end{tabular}

Observa-se na Tabela 4 que 20\% dos idosos, na primeira coleta, mencionaram ter o facebook, no entanto, por não saberem manusear essa rede ainda não haviam construído vínculos de amizade, por outro lado $80 \%$ declaram que nunca tiveram acesso. Vale ressaltar que ter conhecimento prévio sobre 
as ferramentas digitais, não era requisito para participar do Módulo III, uma vez que o assunto seria explorado ao longo da oficina. Com relação ao blog, $65 \%$ dos entrevistados o consideraram como meio de interação com o mundo; $20 \%$ como ferramenta de comunicação; $10 \%$ para aquisição de conhecimento e $5 \%$ para entretenimento.

Na segunda coleta, ao indagar os participantes sobre o facebook como uma ferramenta que os permitia construir laços de amizades, todos afirmaram de modo positivo. Com relação ao blog, $35 \%$ dos participantes consideraram como ferramenta de comunicação; $30 \%$ como forma de adquirir conhecimento; $15 \%$ como meio de interação com o mundo; $10 \%$ para entretenimento; e $5 \%$ pela facilidade e outras contribuições.

Diante dos dados, percebe-se que, após o Módulo III, da oficina Idosos On-line, os participantes modificaram as suas percepções a respeito dos vínculos e das contribuições oferecidas pelas redes sociais.

Vale ressaltar que, por intermédio da oficina, os participantes desenvolveram um blog coletivo (http://idososblogueiros.blogspot.com.br/) que possibilitou o compartilhamento de informações livres, ou, sobre temas de cunho gerontológico.

Do mesmo modo, o facebook se tornou uma grande fonte de interesse por parte dos participantes, principalmente, aos que consideraram como um forte contributo para fazer novas amizades e promover contatos com familiares e amigos distantes. O uso da internet cada vez mais vem permitindo que pessoas compartilhem informações umas com as outras, mesmo mantendo grandes distâncias (HILT; LIPSCHULTZ, 2004).

Com isso, a internet, por meio das redes sociais, está modificando a maneira como as pessoas se comunicam e se relacionam. Essas redes ligam as pessoas e servem como uma forma de suporte social, uma vez que há frequência de contatos, duração e reciprocidade dos laços estabelecidos (HILT; LIPSCHULTZ, 2004). Dickenson e Hill (2007) identificaram que idosos que utilizavam o computador frequentemente, com a finalidade de se comunicarem, apresentavam maior rede de suporte social apoiada nos amigos e familiares.

Tal inserção fez com que os participantes também desenvolvessem ações ligadas à geratividade e ao desenvolvimento pessoal, conforme observado nas opiniões relatadas por eles: "Aprendi a me comunicar com as pessoas"; "Aprendi muito sobre saúde, alimentação e atividade física"; "Me entrosei com as novas técnicas de informática". 
0
0
0
5
$\square$
$\square$

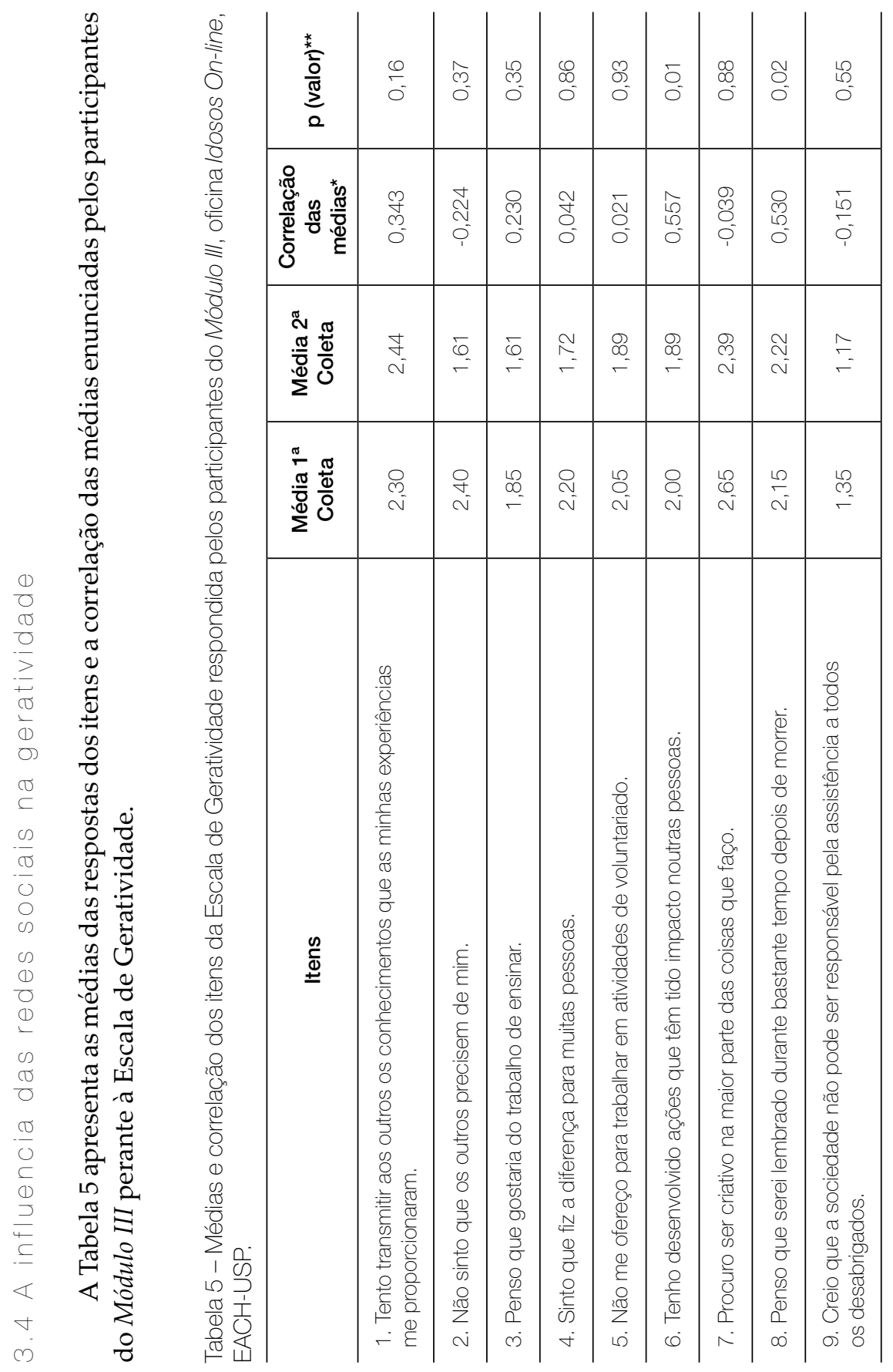




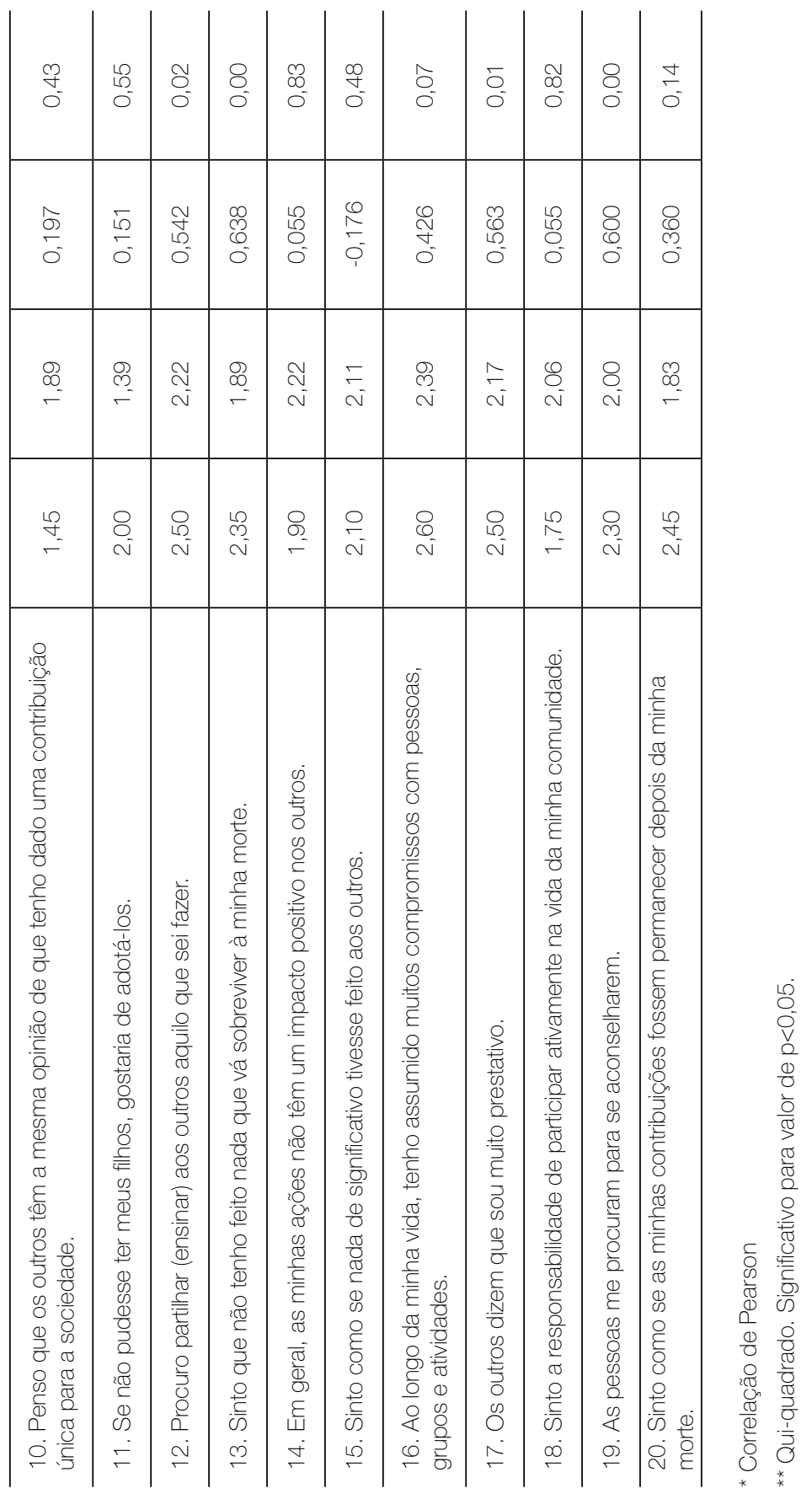


Dos vinte itens da escala, seis apresentaram diferenças estatisticamente significativas entre as médias das duas coletas realizadas (antes e posterior à participação no Módulo III): 1) tenho desenvolvido ações que têm tido impacto noutras pessoas; 2) penso que serei lembrado durante bastante tempo depois de morrer; 3) procuro partilhar (ensinar) aos outros aquilo que sei fazer; 4) outros dizem que sou muito prestativo; 5) as pessoas me procuram para se aconselharem; 6) sinto que não tenho feito nada que vá sobreviver à minha morte.

Na variável "tenho desenvolvido ações que têm tido impacto noutras pessoas" evidencia-se o esforço que os participantes apresentaram, principalmente ao iniciarem o Módulo III, para manterem-se envolvidos em atividades que atinjam as outras pessoas de maneira favorável; algo que possibilite que sejam notados pela próxima geração. Que representem um legado importante (BERMAN, 1995). Expressar seus pensamentos, ideias e aprendizados nas redes sociais, configura essa possibilidade.

Quanto à variável "penso que serei lembrado durante bastante tempo depois de morrer", os idosos expressaram ao participarem do Módulo III, uma tentativa de alcançar a imortalidade, como forma de vencer a morte simbolicamente, de sobreviver eternamente, deixando sua marca no mundo (BERMAN, 1995; NERI, 2005). A ação gerativa é um investimento desinteressado mediante o qual a pessoa valida a própria existência, como se os adultos desafiassem a morte ao desejarem construir legados que permaneçam em qualquer domínio - físico, espiritual e social.

Sobre a variável "procuro partilhar (ensinar) aos outros aquilo que sei fazer" por meio do uso da internet e das redes sociais, os idosos procuraram transmitir essa nova possibilidade de informação. Segundo Erikson, 1998, o adulto maduro preocupa-se em estabelecer e orientar a nova geração, ou então sente empobrecimento pessoal. O estágio gerativo possui grande importância para a transmissão de conhecimentos, para a convivência entre gerações e para um empenho maior por parte da pessoa na transmissão da bagagem cultural acumulada ao longo dos anos vividos.

Com relação à variável "os outros dizem que sou muito prestativo", os idosos expressam que ser significativo para a comunidade é um dos contributos importantes da geratividade, como afirmam Rebelo e Borges (2009). Logo, tal ação gerativa está presente nas atitudes solidárias e prestativas desenvolvidas pelos idosos, principalmente quando há a convivência com a geração mais nova (ERIKSON, 1998).

A variável "as pessoas me procuram para se aconselharem" transpassa o anseio dos participantes ao terem uma sensação de ordem e de direção a ser seguida (BERMAN, 1995). Além de ser um contributo da geratividade, o aconselhamento faz parte da interação e do suporte social que, consequentemente, 
estão presentes nas redes sociais. Envolve a transmissão do que foi criado; no ensino, na orientação, na modelação e no deixar um legado pessoal, permitindo porém o uso autônomo desses produtos pelos beneficiários.

Finalmente na variável "sinto que não tenho feito nada que vá sobreviver à minha morte" evidenciou-se uma redução estatisticamente significativa dos idosos após participarem do Módulo III. Este dado demonstra que envolver-se em atividades que envolvem a aprendizagem de informática e a inclusão nas redes sociais digitais podem gerar um processo facilitador para a geratividade, que inicia-se com o desejo interior de imortalidade, com a preocupação social e com a demanda cultural acerca do tempo e formação da vida adulta, e finaliza com a elaboração das histórias de vida dos adultos que se esforçam em articular seu passado gerativo com a geratividade futura, de si mesmos e para com a comunidade (BANHATO et al., 2007). A internet, por meio das redes sociais, pode ser uma alternativa para a mudança do sentimento de sobrevivência dos seus feitos, uma vez que permite buscar e compartilhar informações que podem vir a ser permanentes.

\section{Conclusão}

O projeto Idosos On-line, por ser um espaço de inclusão digital e intergeracionalidade, atendeu as expectativas dos participantes promovendo, assim, o crescimento pessoal, a troca de experiências e das ações gerativas, por meio da integração, do compromisso e do empenho, conforme as atividades eram desenvolvidas.

Desse modo, os participantes do Módulo III, do Idosos On-line, utilizam e se interessam mais pela internet ao acessarem mais as páginas de notícias, de pesquisa e de busca, de diversão e de educação.

Por fim, ao adentrarem nas redes sociais, o facebook e o blog, os participantes modificaram as suas percepções a respeito das contribuições e associaram a importância dessas, como fonte de comunicação e facilidade para resgatar suas histórias de vida e, consequentemente, estabelecer novas redes de suporte social, de modo virtual.

Contudo, mesmo sendo nítida a observação de ações gerativas com o uso das redes sociais, faz-se necessário desenvolver as questões de geratividade com o intuito de suscitar reflexões sobre essa temática.

Com isso, sugere-se mais pesquisas futuras sobre os contributos da geratividade relacionados ao uso e ao acesso às redes sociais, no sentido de investigar o impacto dessa associação em participantes de atividades intergeracionais e de inclusão digital. 


\title{
abstract
}

The project 'Idosos On-line' is a space of digital inclusion for older people which enables the intergenerational meet and generative actions. It was sought to identify indicators of generativity in old age, as well as the possible impacts and consequences for older people to participate in this workshop. I was applied a socio-demographic questionnaire, a semi-structured questionnaire on computer use and Generativity Scale. Treatment and data analysis were performed by using the SPSS program. The results showed that most participants are women over 70 years, and with incomplete primary education. About the generative actions of the twenty items of Scale, six had statistically significant differences between the means of the two tests performed (before and after the participation in Module III) 1. Have developed actions that have had an impact on other people; 2. I think I'll be remembered for a long time after dying; 3. Try to share teach others what I can do; 4. Others say that I am very obliging; 5. People come to me for advice; 6 . Feel I have done nothing that will survive my death. These participants perceived the social networks as tools for communication, knowledge and interaction with the world. It was found that social networks can contribute to the presence, strengthening, and the pursuit of actions or attitudes that foster generativity.

keywords

Social network. Elderly. Internet. Generativity.

referências

\begin{abstract}
AZEVEDO, Celina Diaz; CÔRTE, Beltrina. Breve reflexão sobre a Internet e a longevidade: novos espaços de sociabilização preparam o silencio da saúde. A Terceira Idade: estudos sobre envelhecimento, São Paulo, v. 20, n. 45, p. 7-37, jun. 2009.

BALBONI, Mariana Reis; SCWARTZ, Gilson. Citizenship and Digital Media Management, Digital Cities III: Information Technologies for Social Capital: Cross-cultural Perspectives. Lecture Notes in Computer Science, Berlin, v. 3081, p. 407-416, 2005.

BANHATO, Eliane Ferreira Carvalho et al. Inclusão digital: ferramenta de promoção de envelhecimento saudável? Psicologia Hospitalar, São Paulo, v. 5, n. 2, 2007.

BERMAN, Harry. Generativity and transference heroics. Journal of Aging Studies, United States, v. 9, n. 1, p. 5-11, 1995.
\end{abstract}


BOULTON-LEWIS Gillian M. et al. Ageing, learning, and computer technology in Australia. Educational Gerontology, United Kingdom, v. 33, n. 3, p. 253-270, Feb. 2007.

BRASIL. Ministério da Saúde. Resolução 196/96 do Conselho Nacional de Saúde/MS Sobre Diretrizes e Normas Regulamentadoras de Pesquisa envolvendo seres humanos. Diário Oficial da União, Brasília, DF, 10 de outubro de 1996.

CAMARANO, Ana Amélia; KANSO, Solange. Envelhecimento da População Brasileira: uma contribuição demográfica. In: FREITAS, Elizabete Viana; PY, Lígia. (Orgs.). Tratado de Geriatria e Gerontologia. 3. ed. Rio de Janeiro: Editora Guanabara Koogan, 2011. p. 58-73.

CETIC BR. Uso das Tecnologias de Informação e Comunicação no Brasil. 2012. Disponível em: <http://www.cetic.br/publicacoes/2012/tic-domicilios-2012.pdf>. Acesso em: 20 jan. 2013.

CHASSOT, Attico. Escrever diários como uma forma de colecionismo. Episteme, Porto Alegre, v. 10, n. 20, p. 55-70, 2005.

CZAJA, Sara et al. Computer-communication as an aid to independence for older adults. Behaviour and Information Technology, United Kingdom, 12, n. 4, p. 197-207, Apr. 1993

DICKENSON, Anna; HILL, Robin. Kepping in touch: talking older people about computers and communication. Journal Educational Gerontology, United Kingdom, v. 33, n. 8, p. 613-630, July 2007.

ERIIKSON, Erik Homburguer. O ciclo da vida completo. Porto Alegre: ARTMED, 1998.

FERREIRA, Alves José et al. Generatividade em estudantes e profissionais de educação. Psychologica, Coimbra, v. 43, p. 143-156, 2006.

FERREIRA, Maria Elisa Caputo; CORRÊA, Jimilly Caputo; BANHATO, Eliane Ferreira Carcalho. Desafios de envelhecer no século XXI. São Paulo: Residencial Santa Catarina, 2010.

GOULART, Denise. Inclusão digital na terceira idade: a virtualidade como objeto e reencantamento da aprendizagem. 2007. 219 f. Dissertação (Mestrado em Educação) - Faculdade de Educação, Pontifícia Universidade Católica do Rio Grande do Sul, Porto Alegre, 2007.

HILT, Michael; LIPSCHULTZ, Jeremy Harris. Elderly Americans and the Internet: e-mail, tv news, information and entertainment websites. Journal Educational Gerontology, United Kingdom, v. 30, n. 1, p. 57-72, 2004.

HOGEBOOM, David et al. Internet Use and Social Networking Among Middle Aged and Older Adults. Journal Educational Gerontology, United Kingdom, v. 36, n. 2 , p. 93-11, Jan. 2010.

JONES, Brett; BAYEN, Ute. Teaching older adults to use computers: Recommendations based on cognitive aging research. Journal Educational Gerontology, United Kingdom, v. 24, n. 7, p. 675-689, Aug. 1998

KACHAR, Vitória. Terceira idade e informática: aprender revelando potencialidades. São Paulo: Cortez, 2003.

MORRELL, Roger; Mayhorn, Christofer; Bennett, Joan. A survey of World Wide Web use in middle aged and older adults. Human Factors, Santa Monica, v. 42, n. 2 , p. $175-182,2000$

NERI, Anita Liberalesso. Geratividade. In: NERI, Anita Liberalesso. Palavras-chave em Gerontologia. 2. ed. Campinas: Editora Alínea, 2005. p. 90-91.

Qualidade de vida na velhice e subjetividade. In: NERI, Anita Liberalesso. Qualidade de vida na velhice: enfoque multidisciplinar. Campinas: Alínea, 2007. p. 13-59 
ORDONEZ, Tiago Nascimento; YASSUDA Mônica Sanchez; CACHIONI, Meire. Elderly online: Effects of digital inclusion program in cognitive performance. Archives of Gerontology and Geriatrics, Ireland, v. 53, n. 2, p. 216-219, 2010.

PÁSCOA, Gina Maria Gouveia. O contributo da web social - rede social Facebook para a promoção do envelhecimento ativo: estudo de caso realizado na USALBI. 2012. 262 f. (Mestrado em Política Social) - Instituto Superior de Ciências Sociais e Políticas, Universidade Técnica de Lisboa, Lisboa, 2012.

REBELO, Piedade Vaz; BORGES, Graciele Franco. Contributos para o estudo do desenvolvimento do adulto: reflexões em torno da geratividade. Práxis Educacional, Vitória da Conquista, v. 5, n. 7, p. 97-114, jul./dez. 2009.

SALES, Márcia Barros. Desenvolvimento de um checklist para a avaliação de acessibilidade da Web para usuários idosos. 2002.121 f. Dissertação (Mestrado em Engenharia de Produção) - Programa de Pós-Graduação em Engenharia de Produção, Universidade Federal de Santa Catarina, Florianópolis, 2002.

SALES, Márcia Barros et al. Alternativa de Inclusão Digital para Idosos: análise de correspondência múltipla para identificação de multiplicadores na aprendizagem por pares. Athena: Revista Científica de Educação, Curitiba, v. 12, n. 12, jan./jun. 2009.

SILVA, Paulo Granges. Estado nutricional e imagem corporal dos idosos cadastrados na Estratégia Saúde da Familia em Campina Grande. Monografia (Trabalho de Conclusão de Curso em Fisioterapia) - Centro de Ciências Biológicas e da Saúde, Universidade Estadual da Paraíba, Paraíba, 2011.

SILVEIRA, Michele Marinho et al. Educação e inclusão digital para idosos. Revista Renote: Nova Tecnologia na Educação, Porto Alegre, v. 8, n. 2, jul. 2010.

WANG, Ling: RAU, Pei-Luen Patrick.; SALVENDY, Graviel. Older Adults' Acceptance of Information Technology. Educational Gerontology, United Kingdom, v. 37, n. 12, p. 1081-1099, Oct. 2011.

WEILAND, Steven. Aged Erikson: The Completion of the Life Cycle. Journal of Aging Studies, United States, v. 3, n. 3, p. 253-262, 1989. 